PNL-7832

UC-402

Requirements Analysis for HEISGIS

\title{
The Geographic Information System Component of the Hanford Environmental Information System
}

S. Tzemos

E. S. Overton

January 1992

Prepared for the

Westinghouse Hanford Company under a Related Services Agreement with the U.S. Department of Energy

Contract DE-AC06-76RLO 1830

Pacifir. Northwest Laboratory

Operated for the U.S. Department of Energy

by Battelle Memorial Institute 


\title{
DISCLAIMER.
}

This report was prepared as an account of work sponsored by an agency of the United States Government. Neither the United States Government nor any agency thereof, nor Battelle Memorial Institute, nor any of their employees, makes any warranty, expressed or implied, or assumes any legal liability or responsibility for the accuracy, completeness, or usefulness of any information, apparatus, product, or process disclosed, or represents that its use would not infringe privately owned rights. Reference herein to any specific commercial product, process, or service by trade name, trademark, manufacturer, or otherwise does not necessarily constitute or imply its endorsement, recommendation, or favoring by the United States Government or any agency thereof, or Battelle Memorial Institute. The views and opinions of authors expressed herein do not necessarily state or reflect those of the United States Government or any agency thereof.

\author{
PACIFIC NORTHWEST LABORATORY \\ operated by \\ BATTELLE MEMORIAL INSTITUTE \\ for the \\ UNITED STATES DEPARTMENT OF ENERGY \\ under Contract DE-ACO6-76RLO 1830
}

Printed in the United States of America

Available to DOE and DOE contractors from the Office of Scientific and Tr:chnical Information, P.O. Box 62, Oak Ridge, TN 37831; prices available from (615) 576-8401. FTS 626-8401.

Available to the public from the National Technical Information Service, U.S. Department of Commerce, 5285 Port Royal Rd . Springfield, VA 22161. 
PNL--', 832

DE92 007604

REQUIREMENTS ANALYSIS FOR

HEISGIS

THE GEOGRAPHIC INFORMATION SYSTEM COMPONENT OF THE HANFORD ENVIRONMENTAL INFORMATION SYSTEM

S. Tzemos

E. S. Overton

January 1992

Prepared for

Westinghouse Hanford Company

under an agreement with

the U.S. Department of Energy

under Contract DE-AC06-76RLO 1830

Pacific Northwest Laboratory

Richland, Washington 99352 


\section{SUMMARY}

The Hanford Environmental Information System (HEIS) has been developed to manage the data from the characterization and environmental monitoring of the Hanford Site. HEISGIS is the Geographic Information Systems component of HEIS.

This report analyzes the HEISGIS functional requirements as articulated by the members of a GIS subcommittee established by the HEIS Technical Advisory Committee (HTAC) in a series of meetings. These functionalities are identified throughout this report, but no implementation commitment is made. This requirements analysis document will be followed by a brief list of the functionalities that will be implemented in FY91 and a description of the requisite acceptance test criteria.

This document states the HEISGIS purpose and objectives; describes the required functionalities and desirable features; identifies some design constraints and assumptions; outlines data requirements and the status of the currently existing data. A preliminary implementation approach and some critical implementation issues are also identified. 


\section{FOREWORD}

The Hanford Environmental Information System (HEIS) has been developed to manage the data from the characterization and environmental monitoring of the Hanford Site. The purpose of the geographic information system (GIS) component of HEIS, termed here HEISGIS, is to allow scientists and engineers to spatially analyze the environmental data stored in the HEIS database.

HEISGIS is in its second stage of development. The first stage produced a working prototype. The focus of the second stage is data accuracy and standardization, analytical and modeling capabilities, improvement of the interfaces between the various software components, and refinement of the user interface.

This report analyzes the HEISGIS functional requirements as articulated by the members of a GIS subcommittee established by the HEIS Technical Advisory Committee (HTAC) in a series of meetings. Some of the requested functionalities will probably not be implemented either because of technical difficulties and limitations of the HEISGIS software development environment, or because they are outside the HEISGIS scope. These functionalities are identified throughout this report, but no implementation commitment is made.

This requirements analysis document will be followed by a brief list of the functionalities that will be implemented in FY91 and a description of the requisite acceptance test criteria.

HEISGIS will be implemented in stages. Each successive stage will result in an increasingly refined system. At the end of each stage, the HEISCIS system will be demonstrated to ensure that the product is what the users expected. 


\section{CONTENTS}

SUMMARY ................................. i ...

FOREWORD ........................... . v

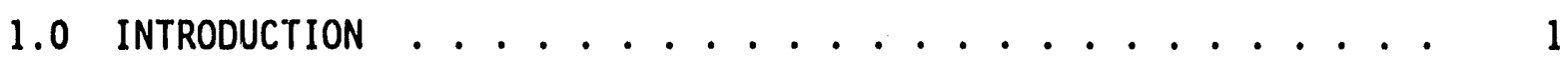

1.1 BACKGROUND ......................... 1

1.2 REQUIREMENTS ANALYSIS PROCESS . . . . . . . . . . 1

1.3 THE HEISGIS ENVIRONMENT . . . . . . . . . . . . . 2

2.0 SYSTEM DEFINITION . . . . . . . . . . . . . . . 3

2.1 PURPOSE AND SCOPE .................... . . 3

2.2 OBJECTIVES ......................... 3

2.2.1 Display Map and Attribute Data . . . . . . . . . 4

2.2.2 Generate New Maps ................ 4

2.2.3 Select Data Based on User-Supplied Limiting

2.2.4 Process Selected Data to Generate New Information. $\quad 4$

2.2.5 Provide a Convenient Source of Reliable Base Maps. 5

2.2.6 Interface with External Systems. ......... 5

2.2.7 Provide Information on Map Accuracy ....... 5

2.3 FEATURES ..................... 5

3.0 FUnCTIONALITIES . . . . . . . . . . . . . . . . . 7

3.1 DATA DISPLAY . . . . . . . . . . . . . . 7

3.2 MAP ACCURACY . . . . . . . . . . . . . . . . 9

3.3 SUBSET DATA BY ATTRIBUTES . . . . . . . . . . . . 10

3.4 COMPARE AND COMBINE DATA . . . . . . . . . . . . 11

3.5 GENERATE THREE-DIMENSIONAL DISPLAYS . . . . . . . . . 12

3.6 CONTOUR ......................... . . 12

3.7 BUFFERING .................... . . . 13

3.8 DIMENSIONAL CALCULATIONS . . . . . . . . . . . . . 14

3.3 INPUT, EDIT, AND OUTPUT USER DATA . . . . . . . . . 14

4.0 DESIGN CONSTRAINTS AND ASSUMPTIONS . . . . . . . . . . . 17

vi i 
5.0 DATA REQUIREMENTS . . . . . . . . . . . . . 18

6.0 IMPLEMENTATION ISSUES ..................... 20

6.1 IMPLEMENTATION APPROACH ............... 20

6.2 IMPLEMENTATION RISKS AND CRITICAL ISSUES . . . . . . . 27

6.2.1 Dead Areas and Boundary Conditions . . . . . . . . 27

6.2.2 Data Security ............... 27

6.2.3 System Response ............... 27

6.2 .4 Contours.................. 28

6.2 .5 Data.................... 28

7.0 REFERENCES ............................. 29

APPENDIX A: USER/ANALYSIS TEAM IDENTIFICATION . . . . . . . . . 31

APPENDIX B: ACRONYMS ...................... . 33

APPENDIX C: FUTURE CONSIDERATIONS . . . . . . . . . . . . . . . 35 


\section{FIGURES}

1. HEISGIS System Overview ................ 21

2. Group 1 Functional Diagram .............. 22

3. Group 2 Functional Diagram .............. 23

4. Group 3 Functional Diagram ............... 24 


\subsection{INTRODUCTION}

\subsection{BACKGROUND}

The Hanford Environmental Inforination System (HEIS) is a repository for scientific and technical data related to Hanford Site cleanup and environmental monitoring. The system is intended to be both a repository for these data and to support analysis and presentation of the data via reporting, graphics, data extraction, and the geographic information system (GIS). The GIS component of HEIS is called "HEISGIS" in this document. HEISGIS will allow for powerful analysis, manipulation, and display of HEIS data and Hanford map data.

The HEIS is being developed through a coordinated effort between Westinghouse Hanford Company (WHC) and the Pacific Northwest Laboratory $(P N L)^{a}$. The system has been under development for three years. The first year was a scoping year. During the second year, a database prototype was implemented. In the third year, the production database portion of the system and the HEISGIS prototype were implemented. This year, a production GIS is being ir.plemented and database capabilities are being expanded.

Because the vast majority of the HEIS data is related to a location on the earth, the GIS is a very important analytical and display tool. The GIS allows the data to be displayed and manipulated geographically. The analytical power of the HEISGIS will help the Hanford environmental engineers, scientists, and managers become more productive in their respective fields.

\subsection{REQUIREMENTS ANALYSIS PROCESS}

Requirements for the HEISGIS were gathered from a subcommittee of representatives of various organizations dedicated to environmental monitoring and restoration. They include geologists, biologists, hydrologists, statisticians, geoscientists, and cartographers. This subcommittee was commissioned by the HEIS Technical Advisory Committee (HTAC) and was responsible for defining the requirements for the HEISGIS.

(a) Pacific Northwest Laboratory is operated for the U.S. Department of Energy by Battelle Memorial Institute under Contract DE-AC06-76RLO 1830. 
The HEISGIS development team met repeatedly with the GIS subcommittee as a group and with individual members of HTAC. The user needs were analyzed and the requisite HEISGIS functionalities to meet the user needs were derived. The HEISGIS functionalities are discussed in this document with examples that explain how the user needs can be satisfied. Thus, when the HEISGIS development team designs and implements the HEISGIS software, it will be able to rely on a complete picture of what each functionality is expected to provide. The HEISGIS requirements detailed in this document will provide the basis for the acceptance criteria for testing the HEISGIS design.

The HEISGIS purpose, objectives, and features are described in Section 2.0. The functionalities are explained in Section 3.0. Section 4.0 identifies some design constraints and assumptions. Section 5.0 outlines data requirements and the status of the currently existing data. A preliminary implementation approach and some critical implementation issues are identified in Section 6.0. Appendix A lists the members of the HEISGIS development team and the HTAC, while Appendix B provides a list of acronyms.

\subsection{THE HEISGIS ENVIRONMENT}

HEISGIS is implemented using the ARC/INFO GIS, a product of the Environmental Systems Research Institute (ESRI). The hardware development platform is a Sun workstation with the UNIX operating system and a windowing environment.

HEISGIS will access the HEIS database through the ARC/INFO RDBIO module and a network connection to the HEIS database. The latter uses the Oracle relational Data Base Management System (DBMS) on a Sequent multiprocessor hardware platform. 


\subsection{SYSTEM DEFINITION}

\subsection{PURPOSE AND SCOPE}

The purpose of HEISGIS is to provide the means to graphically manipulate, store, display, and analyze the spatially distributed data of HEIS in order to facilitate modeling, understanding, and communication concerning the Hanford Site.

The scope of HEISGIS is defined by the spatial information needed for environmental monitoring and restoration of the Hanford Site in support of the milestones set forth by the Hanford Federal Facility Agreement and Consent Order (known as the Tri-Party Agreement).

HEISGiS has the following two goals.

- The first goal is to support the spatial data storage, display, and analysis needs of current and future envircimental monitoring and restoration activities. The users will rely on the HEISGIS accuracy, modeling tools, mapping, and interface with the nonspatial attributes of HEIS for their modeling and information needs.

- The second goal is to enhance communication. The high quality graphical output will be used to help present environmental monitoring and restoration results to the scientific community and the general public as well.

Some examples of technical applications of the HEISGIS are:

- display and data analysis for each of the major HEIS subject areas including atmospheric, biota, geologic, geophysics, ground-water, soil gas, and well-construction data

- interface with working copies of current maps maintained in the Spatial Information Management System (SIMS)

- support of environmental studies including environmental assessments and long-term environmental monitoring.

\subsection{OBJECTIVES}

The need to depict and analyze spatially distributed information became apparent during the development of the HEIS database. However, a relational database is not the forum for storage, retrieval, and manipulation ui spatial data. Therefore, the HEIS database contains only references to locations in 
space, while HEISGIS contains all the spatial data and the tools to manipulate them. The objectives of the HEISGIS were set by the GIS subcommittee of HTAC after a series of meetings with representatives from the potential HEIS user community

\subsubsection{Display Map and Attribute Data}

HEIS contains data from environmental investigations and contamination monitoring. HEISGIS will provide the capability to graphically represent data stored in HEIS as well as the means to display maps such as those displaying the Hanford Site's geology, hydrology, biota, and the results of geophysics investigations. HEISGIS will provide a graphical representation of the data currently stored in HEIS as well as display maps currently being developed at the site. The HEIS data will be superimposed on the site maps for a better understanding of their spatial distribution.

\subsubsection{Generate New Maps}

HEISGIS will allow the user to generate new maps by modifying exicting maps through edicing or overlays, by digitizing paper maps, or by transferring digital data through the AutoCad interface. The new maps will reside in the user's private space and will be accessible only by a limited number of authorized users. The user maps will not become part of the HEISGIS system unless it is so requested, the needed storage space is available, and the maps are verified and validated.

\subsubsection{Seiect Data Based on User-Supplied Limiting Criteria}

One of the fundamental aspects of any GIS is to be able to view data according to some attributes or combination of attributes of the data. For example, display only those wells in the 1100 Area with a depth of $3 \mathrm{~m}$ or more. The user will supply limiting criteria to restrict the displayed data. The user will also be able to interact with the display to select a subset of the data to be viewed or manipulated. For example, the user may use the mouse to designate an area on the screen that contains a subset of wells for which additional information is desired. 


\subsubsection{Process Selected Data to Generate New Information}

The user will be able to combine different map data sets to create new maps that can then be stored for later viewing, analysis, or additional modifications. For example, the overlay of a map layer with facility discharge stack iocations and layers with atmospheric data might identify facilities that are good candidates for exhaust system maintenance or upgrades.

\subsubsection{Provide a Convenient Source of Reliable Base Maps}

The user is able to access up-to-date base maps easily and copy or work with the maps of interest. The original system data is kept intact and can only be changed by the users with data update privileges. This data security process enables users to use the HFISGIS without corrupting any of the system data.

\subsubsection{Interface With External Systems}

HEISGIS will allow for interfaces with external systems and software packages. For example, HEISGIS will have an interface with the HEIS database that is transparent to the user (known as a seamless interface). HEISGIS will support information transfer from and to AutoCad files in Autocad's Data Exchange Format (DXF). ACCII files will be the standard interface format for any other software package, such as statistical packages, three-dimensional modeling packages, and other graphics packages.

\subsubsection{Provide Information on Map Accuracy}

The accuracy of the data being viewed or manipulated is important information to the user. HEISGIS will supply descriptions of spatial data accuracy. The accuracy statements made by HEISGIS will be based on the information provided by the original source of the spatial data. Where possible, the original sources will be referenced.

\subsection{FEATURES}

Characteristic features of the HEISGIS are 1isted below. Some of these features have already been implemented in the existing prototype while others will be implemented in the future. 
- HEISGIS will provide a seamless interface to the HEIS database. It will ailow the user to access the HEIS database, to select and display the HEIS data on a map, and to study the complex environmental interactions due to spatial proximity.

- The standard Washington State plane coordinate (WSC) system with a Lambert NAD83 metric projection is being used throughout the HEISGIS.

- High resolution color graphics on the screen, plotter, and thermal printer will provide high quality output.

- A large format digitizer will allow large size paper map digitization.

- Data will be displayable in special graphics windows.

- Audit trails will be available to allow effective quality assurance.

- Map accuracy information will be displayed on the map.

- The user interface will be of the point and click variety with the possibility for a command line interface for sophisticated users.

- The HEISGIS will have the ability to import and export files in the AutoCad DXF format.

- The HEISGIS will provide appropriate security on all HEISGIS map data. Users will work with copies of the system data and will be able to digitize their own maps. 


\subsection{FUNCTIONALITIES}

\subsection{DATA DISPLAY}

Area Maps. A map of the entire Hanford Site needs to be available with the approximate locations of major site features. The site map will be used for basic user orientation on the site and the identification of areas or features of interest. Layers of the site base map include the Hanford Site boundary, major site roads, major water bodies, and other clearly identifiable site features of general or special interest. More detailed and accurate information will be available for the following areas:

100

$200 \mathrm{E}$

$200 \mathrm{~W}$

300

400

i100

The 600 Area consists of sites not included in the aforementio.red areas and will only contain general map features at this time. Currently there is no good spatial information source for the 600 Area. An attempt will be made to acquire rasterized SPOT satellite images to form a backdrop for the entire Hanford Site. If SPOT data are not acquired, existing data will be edited to show the site boundary, major water bodies, and the afo!ementioned numbered areas.

Coordinate Systems. The HEISGIS standard coordinate system is a Lambert projection of the Washington Coordinate System of 1983, South Zone (WCS83s), and the coordinates are expressed in meters. The WCS83s is based on the North American Datum of 1983 (NAD 83).

It is noted here that a multitude of coordinate systems have been used at the Hanford Site over the past 50 years. Most of these coordinate systems are known with the collective name "Hanfoid Coordinate Systems" (HCS). Other "local" coordinate systems that have been usid are the $\mathrm{N}$-Area coordinates, Plant coordinates, and Richland coordinates. The degree of completeness and accuracy of the Hanford maps in the aforementioned coordinate systeins varies significantly. 
Much essential environmental information refers to locations that are recorded in one or more of the Hanford coordinate systems. Accurate transformations between coordinate systems is possible only where there exists a good field tie between the coordinate systems, and it must be in the particular vicinity under consideration. Therefore, procedures and algorithms need to be developed (outside of HEISGIS) that will allow the translation of a limited number of locations from the Hanford coordinate systems to WSC. An example of locations that need to be translated are sume of the Hanford well locations. Of the over 3,000 Hanford wells, only a handful of wells are currently recorded in the WSC. Most of the wells are in plant coordinates.

Digital Elevation Data. Digital elevation contours will be entered in HEISGIS in the form in which they have been validated to retain maximum accuracy. This information will be provided by Engineering Services and SIMS.

Map Layers. It is expected that the maps that HEISGIS will receive from SIMS will contain more map layers than required by the HEISGIS users. Therefore, early in the design process, the HEISGIS users will be asked to identify which map layers are desired. Some examples of the general map layers to be displayed are:

- general area boundaries

- roads

- wells

- waste sites

- location of selected utility features

- surface and subsurface geology and hydrogeology where available

- building perimeters.

other available map features that are pertinent to environmental monitoring and restoration can be added as budget and schedule permit.

Geophysics Measurements Resulis. Geophysics measurements generate massive amounts of data that cannot be stored efficiently in a traditional database or GIS. However, the interpreted results of the measurements include outlines and profiles which can be stored and displayed as a map overlay in a pop-up window or possibly on the ground map in a 30 projection. 
The geophysics measurements include seismic, ground-penetrating radar (GPR), gravity, magnetic, and electromagnetic induction (EMI) data. Where the volume of data precludes storage of the entire data set in the database, interpreted results can be digitized and stored in the database as follows.

- Seismic data will be represented by the trace of the seismic line on the map. The seismic trace could also represent the locition of interpreted data which would be comprised of a number of lines representing geologic layers.

- Gravity data will be a grid of profiles with points $3 \mathrm{~m}$ to $400 \mathrm{~m}$ apart. This data is based on a common $\mathrm{pl}$ ane and can be contoured.

- GPR data stored in the HEIS database are the end points of the line on which the measurements were taken, and a reference to where the data are located. The interpreted results can also be stored as outlines.

- Magnetic data--the $x, y$, and $z$ values are stored in the HEIS database.

- EMI data--the $x, y$, and $z$ values are stored in the HEIS database.

Graphics. Graphical displays, such as skyscraper plots or bar graphs, may be superimposed on area maps or in separate screen windows. Graphics displays may be used to depict data variation and trends in space and time.

\subsection{MAP ACCURACY}

Most of the HEISGI's maps are received from WHC Engineering Services. The Engineering Services maps are made according to the National Map Accuracy Standard (Ref. 2). Map accuracy for the HEISGIS has been defined as follows:

$1.0 \mathrm{~m}$ or scale of $1 / 2,000$ for active waste sites within the site

$5.0 \mathrm{~m}$ or scale of $1 / 10,000$ along the river and in all aggregate areas

$10.0 \mathrm{~m}$ or scale of $1 / 20,000$ for everything else.

Let the distance between two well-defined points $A$ and $B$, measured on the map, be $A B_{m}$. The true distance between the same two points, measured on the earth's surface using surveying instruments and techniques of adequate accuracy, is $A B_{t}$. If $A B_{t}-1.00 m<A B_{m}<A B_{t}+1.00 m$, then $A B$ is represented on the map with an accuracy of $1.00 \mathrm{~m}$.

The digital eievation data will have contours every $0.5 \mathrm{~m}$. 
The HEISGIS maps will meet the National Map Accuracy Standards. All map data provided in the HEISGIS will be characterized by statements of accuracy and pedigree. Where pedigree information is extensive, the user will be referred to the user's manual or supplemental screen windows.

It is likely that the accuracy of some maps will be unknown or below standard because the maps are derived from older maps. If accuracy is unknown, this will also be stated. When two or more map layers are combined, the resultant map will assume the accuracy of the least accurate of the original maps. HEIS data associated with the HEISGIS maps will retain the accuracy with which the data are stored in the HEIS database.

The map data display will be comniensurate with the map accuracy. Maps displayed on the screen are based on original maps drawn on Mylar. When the distance between two points on the screen is bigger than the distance between the same points on the original Mylar, the map objects may appear distorted. A warning statement will be issued notifying the user that the map enlargement on the screen is larger than the map original.

\subsection{SUBSET DATA BY ATTRIBUTES}

This is c'afined as the ability to view and/or manipulate only a portion of the data. The needed subset will be derived through some user-supplied criteria. The subsetting criteria may relate to the data attribute values or to their associated location on the map. For example, subsetting criteria may be the constituent range of values, environmental characteristic, sampling date, distribution area, or specific well location. The subsetting criteria may be applied one at a time or in combinations of several criteria related through Boolean operators such as AND, OR, XOR, and NOT. The selected data can be saved for future reference.

The subsetting queries will be mostly menu driven. For special cases where the HEISGIS subsetting process is inadequate to identify specific data sets, the user will be allowed to exit the HEISGIS environment temporarily and access the HEIS database directly. The user will thus create temporary data sets that will subsequently be accessed by the HEISGIS.

There are three categories of results from subsetting the data: 1) data 
appeared because it met the selection criteria; 2) data did not appear because it did not meet the selection criteria; and 3 ) data did not appear because there was insufficient data in the database. HEISGIS will only show the results that satisfied the selection criteria (category 1). The user will have to examine the data to determine whether the data did not appear because they did not meet the subsetting criteria or because they have not been entered in the database.

\subsection{COMPARE AND COMBINE DATA}

The Compare and Combine Data functionality is defined as taking different data sets and putting them together in some useful fashion to create new data sets. The following functions will be provided to the user.

- Unions-..the union of two data sets is the set containing all the data from the original data sets.

- Intersections--the intersection of two data sets is the set containing the data that are included in the area common to both of the original data sets.

- Combine/compare distributions in space and time--the user may be able to combine the spatial distributions of two constituents and identify a combined area of interest by overlaying constituent contour maps. For example, given the areas contaminated with hazardous material $A$ and the areas contaminated with material $B$, it may be decided that, due to the possible interactive nature of $A$ and $B$, the areas contaminated with both $A$ and $B$ should be restored using a different technology than the technology used for the restoration of either $A$ or $B$.

The same selection process may be applied to constituent samples taken at different times. Thus, for example, the rate of contamination of an area with a specific contaminant may be identified.

- Thiessen polygons--Thiessen polygons are used in proximity analysis. Given a set of regional centers, the Thiessen polygon of each center is the loci of the points that are closest to the center.

- Subtraction--when combining or comparing data sets, additional subsetting will be allowed. An example would be to simply view all the wells in a certain area and then view them again only without certain wells such as those with a minimum level of a constituent. 


\subsection{GENERATE THREE-DIMENSIONAL DISPLAYS}

Surface models using three-dimensional views and draping will be displayed. The inherent limitations of the ARC/INFO software that is used in the development of HEISGIS allows a limited manipulation of three-dimensional surfaces. The ARC/INFO capabilities are referred to as 2-1/2 dimensional. They allow the representation of convex surfaces whose bottom side is flat. Concavities are not allowed. Representation of the cross sectional surfaces of solids are also not possible within ARC/INFO.

The ability to profile attribute data on user-defined map cross sections will be supplied. The profile will be a chart depicting the surface $z$ values on the absisca and the length of the user-defined cross section on the ordinate.

\subsection{CONTOUR}

Contouring may be defined as a two-dimensional representation of threedimensional data. The third dimension, the $z$ value, is not limited to elevation. It will represent values from database attributes such as groundwater, geologic, biota, atmospheric, or soil gas data. The contours will be used to interpolate between the points and estimate the distribution of the attribute data.

It is expected that contours will be widely used by the HEISGIS users. Therefore, it is important that the contour definition user interface be complete, flexible, and robust.

The following subfunctions of contouring will be supplied.

- Slope--the slope of a surface can be found and displayed.

- Aspect--slope direction of selected data can be found and displayed.

- Boundary conditions--the HEISGIS will provide the boundary condition specification capabilities provided by ARC/INFO.

- Labeling--labeling and coloring of the contour lines will be supplied. The type of $z$ value displays and the color of the lines may vary with the $z$ value to depict the $z$ value changes. For example, as the vegetation concentration ( $z$ lalue) increases, the line color may change from light green to darker green to dark brown. 
- Dead areas--dead areas are geographic areas that exhibit unusual behavior and possibly a discontinuity with respect to the contoured attribute. For example, when the contoured attribute is elevation, a lake in the middle of mountains is a dead area. HEISGIS will handle the representation of dead areas. At a minimum, dead areas will be ignored by the contouring algorithm. However, it is recognized that contouring algorithms that are appropriate for depiction of elevation variations may not be appropriate to represent other constituent data. For example, geologic faults may be best represented by two sets of data on lines very close together, but on the opposite sides of the fault. The treatment and identification of dead areas, boundary conditions, and smoothing techniques will be established through further interactions with the users and will be restricted by the capabilities of ARC/INFO. Identifying dead areas and boundary conditions is expected to be an ongoing effort.

- Further analysis--the HEISGIS will provide for the conversion of contoured date into polygon data so that additional analys is may be performed such as:

- contour overlays with other spatial data distributions

- editing of the contours to remove outliers and known modeling defects

- comparison of the contours of different constituents or of the same constituent at different sampling times

- combination of contours of different sets of point data

- identification of areas with similar slope and aspect

- combination of contours with skyscraper or bar graph data displays.

- User prompts--at a minimum, the user will be prompted to select the data to be contoured; the minimum, maximum, or interval values; and the interpolation algorithm.

- Units conversion--all map data will have to be converted to metric before entering the HEISGIS system.

- Accuracy--the possibility of generating contours commensurate with the constituent and map data accuracy will be investigated.

\subsection{BUFFERING}

The HEISGIS will provide buffering capabilities for point data, polygonal data, and arc data. The user will be prompted to enter the width of the buffer zone once the data to be buffered has been selected. 


\subsection{DIMENSIONAL CALCULATIONS}

The user will select the type of analysis and the specific features for analysis. The user will also have the option of storing the results of the calculations.

The following types of calculations will be supported:

- length

- area

- volume--this will only be estimated where 2-1/2 dimensional

representation is adequate. True three-dimensional volume calculations may be done through interfacing with third party software. The restriction to 2-1/2 dimensional representation is a generic limitation of the ARC/INFO software package.

- perimeter

- depth

- percent area of certain features

- count--a count of the number of features

- minimum, maximum, and average length and width for regu?ar and irregular features.

\subsection{INPUT, EDIT, AND OUTPUT USER DATA}

Two kinds of data are addressed in this functionality: map data and the HEIS database attribute data. The latter has well-established and welldocumented (WHC 1990) procedures for entering, editing, and accessing data. HEISGIS will establish similar procedures for the manipulation of the map and map attribute data.

It is recognized that data security issues are very important to the HEISGIS users. Therefore, each HEISGIS user or group of users will have a privately owned user space with strictly controlled access privileges. Proper data security measures will ensure that the user and system-controlled data are not corrupted intentionaily or inadvertently by unauthorized users.

Input. The user will be able to enter new map digital data in one of the following ways: 
- through a digitizer

- using the HEISGIS interface to AutoCad and reading data in DXF format

- using the generic interface and reading digital data in ASCII format

- by copying data from the HEISGIS system file to the individual user space for further editing and manipulation.

Copying the system files allows the user to create new maps without having to start from scratch. Whatever the mode of data entry, the user will have to determine and declare the map accuracy. As sonn as a HEISGIS set of map data is edited, its original accuracy is invalidated.

Edit. There will be two levels of data editing: the regular user level and the superuser level. The regular user level will allow only a limited set of menu-driven editing capabilities, but it will be easy to learn and do. The superuser level will provide substantially more editing functions, but it will demand more commitment in training, more responsibility in safeguarding the user-developed data, and it will be less forgiving of the user's mistakes.

The user will have a capture option to record all steps taken while the capture option is on. This record can then be saved or printed.

For map data, the following functionalities will be supported:

- turning data off or on--this allows only selected data to be viewed or manipulated (see Subsetting Data)

- changing layer display characteristics--e.g., the color, line type, fill type, font, etc.

- creating or deleting new map data layers through digitizing or on-line editing

- editing contours, e.g., changing or deleting contour lines or simply moving them.

Qutput. As implied in the aforementioned data entry functionalities, HEISGIS will establish data transfer (both input and output) capabilities within DXF format for AutoCad and in a generic ASCII format to interface with other software packages. The possibility of establishing binary format interfaces with the Statistical Analysis System (SAS) and Dynamic Graphics software will be investigated. 
The primary output device of HEISGIS is the terminal display screen. HEISGIS will also be able to produce high quality paper maps on a pen plotter or a thermal printer and transparencies for presentations. The quality of the output capabilities is determined primarily by the avallability of high quality output devices. 


\subsection{DESIGN CONSTRAINTS AND ASSUMPTIONS}

Design constraints are physical restrictions which restrict analysts, designers, and programmers from producing the desirable product. Product quality is constrained by limitations regarding hardware and software, funds, delivery dates, data, and personnel avallable. Design constraints and assumptions for the HEISGIS are as follows.

Hardware/Software Constraints and Assumptions.

- ARC/INFO Beta Version 6.0 will be used as the HEISGIS software platform. It is assumed that ARC/INFO Version 6.0 , at least in the beta release form, will be avallable to WHC by October 1, 1991.

- The HEISGIS will be developed on a Sun 4/330 and Sun Sparc Stations using ARC/INFO, X-Windows, and the UNIX operating system.

- The HEISGIS will access HEIS data stored in Oracle on the Sequent computer.

\section{Dates/Deliverables Constraints and Assumptions.}

- An operational HEISGIS will be delivered for user acceptance and testing on September 30,1991 . Further development is anticipated in the following years.

- The final maps will be incorporated in the HEISGIS system as they become available and at a pace agreed to by PNL and WHC. HEISGIS can be tested using the sample data from the 200 Areas.

Data Constraints and Assumptions.

- Any data not provided from Engineering Services (WHC) by May 1, 1991, will not be incorporated in the delivered product. The HEISGIS system will be delivered for testing with an agreed set of sample data.

- All map data will have to be supplied with an accuracy reference.

- Pedigrees of maps will be provided in a HEISGIS reference manual. Functionality Constraints and Assumptions.

- A working system with fewer functions is preferable to an incomplete system with more functions. 


\subsection{DATA REQUIREMENTS}

The HEISGIS uses two types of data. The first data type is base map data that identify the location of general map features: area perimeter, roads, buildings, elevation contours, major water bodies, etc. The second data type refers to map data of special user interest, e.g., water level contours, ground-water, geologic boundaries, biota, vegetation/habitat, etc. HEISGIS is responsible for providing the base map data to the HEIS user. The special interest data will be determined by the HEISGIS users using the functionalities outlined in Section 3.

The existing base map data for the entire Hanford Site is of uncertain quality and unknown accuracy. An effort will be made to clean up the data so that it can be used for user orientation and to locate the individual waste sites within the Hanford Site boundaries. A copy of a rasterized SPOT image may be obtained to be used as a backdrop for the entire site and to help the aforementioned site data cleanup.

The present Hanford Site map is too general and inaccurate to be used in most of the expected HEISGIS applications, but.will serve as a reference for the individual aggregate areas. Whenever specific information is requested, it will be provided by more detailed maps for the area of interest. These maps are made available to HEISGIS by the SIMS project of WHC's Engineering Services. Data from the 100, 200E, 200W, 300, 400, 600, and 1100 Areas will be supplied to the user as soon as they are verified and entered in HEISGIS. The 600 Area is generally considered to be the entire site except for the areas numbered 100 through 3000.

The existing data for the aforementioned area maps are in different stages of completion. The process they go through is as follows.

1. Kaiser Hanford Engineers Company (KEH) contracts out the aerial flyovers of each area.

2. KEH verifies the photogrametric maps and then sends them in AutoCad format to WHC Engineering Services.

3. Engineering Services processes the maps in these steps: 
a. add annotations to the map

b. break the map into disciplines

c. break the data geographicaliy into large map sheets

d. add attribute identifications.

4. Engineering Services sends the maps to the HEIS development team in Autocad forinat. The HEIS development team then transiates them to ARC/INFO format.

Base map data availability for the major areas are as follows.

- 100 Area--KEH has delivered raw data to Engineering Services

- 200 Area--the 200E, 200W, and the area directly between them have been delivered to WHC Engineering Services.

- 300 Area--Engineering Services currently has raw data.

- 400 Area--Engineering Services currently has raw data.

- 600 Area--the site base map discussed above will be used.

- 1100 Area--HEISGIS is using an older map for the 1100 Area which was used in the FY90 prototype. The aerial survey was done in NAD83 feet, its contours are in feet, and there are not as many layers as in later surveys. The map accuracy is unknown. This data has already been converted to ARC/INFO format and will be used if newer data is not available.

There are many old maps currently at WHC that are in Hanford coordinates. Most of these maps will never be used in the HEISGIS. However, if and when they are needed, they will need to be converted to the HEISGIS standard coordinates and supplied to the GIS team on an as-needed basis and as a result of a user's request. They will be labeled according to whatever accuracy can be determined. 


\subsection{IMPLEMENTATION ISSUES}

\subsection{IMPLEMENTATION APPROACH}

This section describes the approach to be taken for implementation of the design requirements. The types of data structures to be used and the programming technique to be followed are also described.

The HEISGIS will be developed using the ARC/INFO software on the UNIX platform. It will utilize a menuing user interface. The design will be modular. The user interface will control the calls to each function and supply it with the necessary parameters. The modules described below form three implementation groups. These module groups will be implemented in the sequence listed. As the design progresses, the users will be updated and invited to comment on it. As the various modules are implemented, demonstrations will be given to the user community. As appropriate, the modules will be modified to incorporate the user's feedback.

The first module to be developed will be the user interface (UI). The UI will be implemented with references ("stubs") to the other modules which may not yet exist. The UI will be more of a "living" module than the others because of its interactions with other modules. The completed UI will not be available until all other modules are finished. The stubs in the UI will be replaced with the corresponding modules as the modules are developed.

Figure 1 shows the overall structure of the HEISGIS system. The user interacts with the system through the user interface, which drives the rest of the modules depending upon the user input. This figure does not depict the interactions between the modules. The interactions between the modules and more detail about the modules are depictea in Figures 2, 3, and 4.

As shown in Figure 1, the UI will be the driving module. It will accept all input from the user and will supply output to the user. The other modules to be designed and implemented will be done in three groups as follows. 


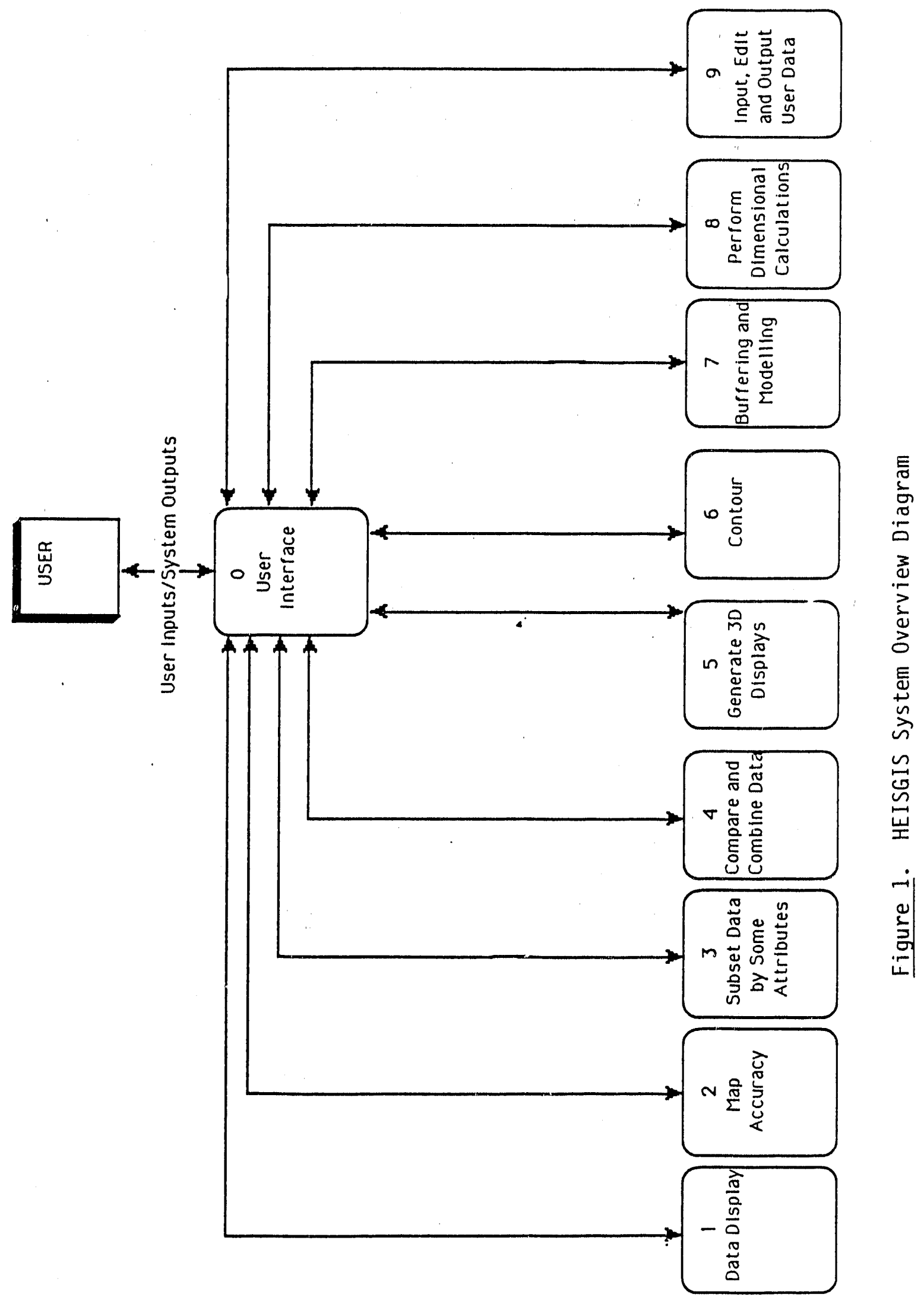




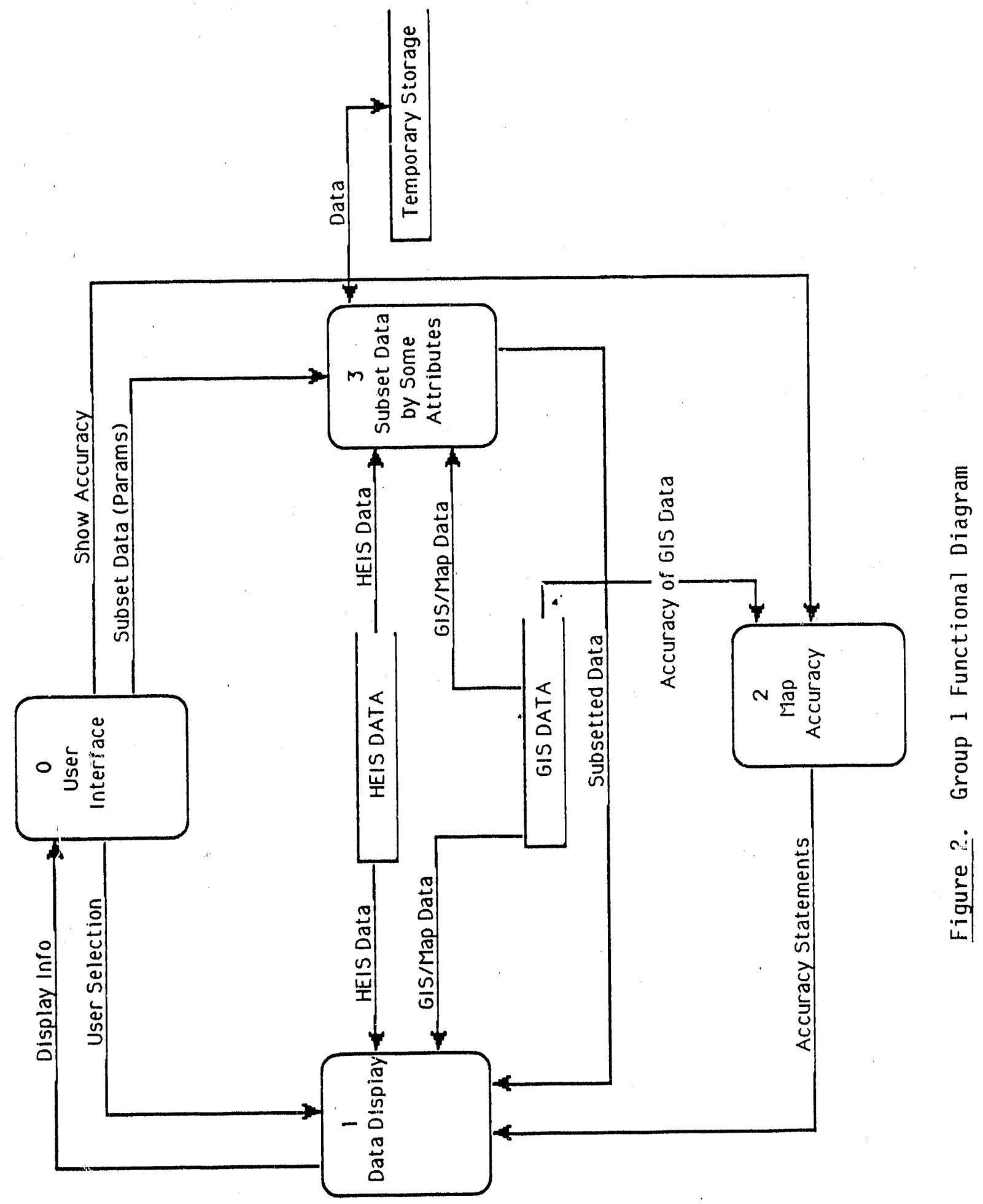




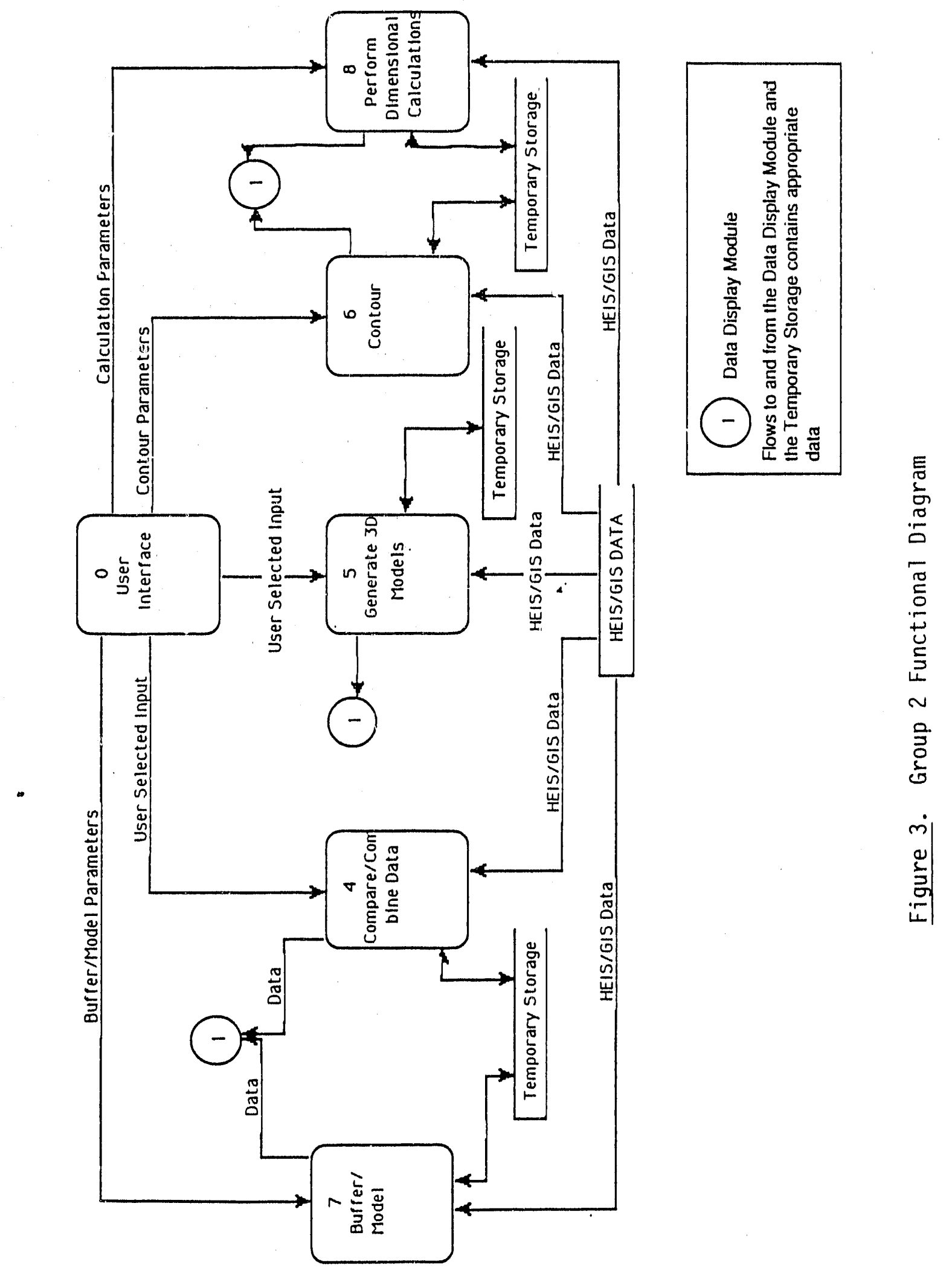




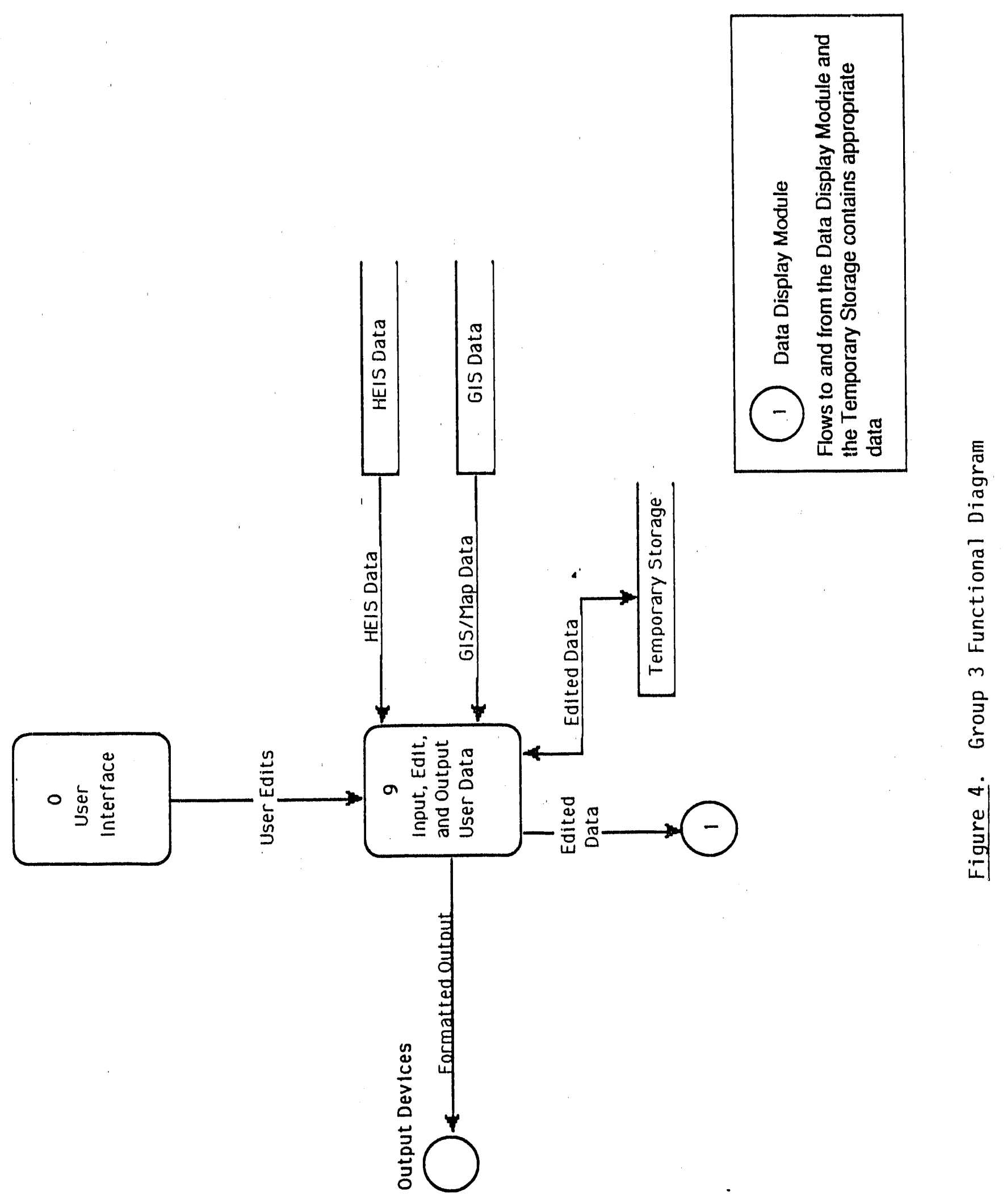


Group 1. The madules in this group correspond to the following functionalities.

- Display spatial and attribute data--this process displays all information to the screen.

- Determine map accuracy--this process acquires accuracy information from the map attribute database or determines the accuracy of data combinations from the accuracies of the component data sets. The pertinent accuracy statements are then provided to the Data Display module.

- Subset data by some attributes--this module takes the data to be subsetted from the user interface, selects the data according to the parameters given, and then sends the data to the Data Display module or to Temporary Storage.

Figure 2 depicts the interactions among the modules of Group 1. The modules interact with each other through data that passes between them. Most modules allow for output of their products either to a printer or plotter or to a file for electronic storage or manipulation.

There are three data stores: HEIS DATA, GIS DATA, and Temporary Storage. HEIS DATA is the data contained in the HEIS database. GIS DATA is the map data stored in the ARC data structures and map attribute data stored in INFO. ${ }^{b}$ Temporary Storage is where user-selected interim data is stored. This data can be used by other modules, printed, or saved for future access.

Group 1 will be finished first because of its impact to the rest of the system. Everything generated by the system must be displayed. Map accuracy statements must be provided to validate the map displays. Subsetting data is the first step in data analysis.

Group 2. The modules in this group provide the following analysis capabilities:

- compare and combine data

- display three-dimensional views

- generate contours

- perform dimensional calculations

- perform buffering and modeling.

${ }^{b}$ INFO is the database portion of th: ARC/INFO software. 
This group is implemented next because it depends on previous functions to be completed. For example, dimensional calculation should follow data subsetting, and buffering would require a data set selected to be buffered around.

Figure 3 shows the modules in Group 2 and their interactions. The user interaction with the user interface is implied, but not explicitly shown on the diagram. For details on each process, see the functionalities descriptions in Section 3.

There are still two data stores, HEIS DATA and GIS DATA, but they were combined and shown as "HEIS/GIS DATA" to make the diagram easier to read.

As shown in Figure 3, all the processes can send their output files to the Data Display module, or to temporary or permanent disk storage, or to other modules for further analysis or hard-copy output.

Group 3. This group contains only one module as follows:

- to perform input, editing, and output operations.

Figure 4 shows Group 3 and its details. This diagram shows the interaction of the user interface and the editing module. Once again, the interaction between the user interface and the user is implied. The editing module can accept data from other modules or directly from the user; the data may be edited and then sent back to other modules or to output devices.

Each of the aforementioned groups will go through a preliminary and then a final design stage. Implementation will follow. The implementers will be in constant contact with selected users throughout the module development and testing. A design workshop at the start of the implementation phase will familiarize the selected users with the HEISGIS design and offer an initial opportunity for feedback. Each group of modules will be tested internally by the implementers following a formal test procedure according to the PNL QA requirements. The software will then be provided to the users for acceptance testing according to the WHC QA procedures.

Most users will access the system through the provided user interface. However, "Enhanced Capabilities Users" (ECU) will be able to also access ARC/INFO through the ARC/INFO shell. Since no user training will be provided 
by the HEIS project, it will be the responsibility of each ECU to understand the ARC/INFO environment.

\subsection{IMPLEMENTATION RISKS AND CRITICAL ISSUES}

\subsubsection{Dead Areas and Boundary Conditions}

Dead areas and boundary conditions are currently an ongoing research topic for the GIS community. Dead areas and forced boundaries cause certain analyses to be inaccurate. For example, a lake may cause a break in the elevation contours of the surrounding mountains. If the lake boundary is not recognized explicitly, the contouring algorithm will ignore it and show elevation contours passing through the lake. An example of a forced boundary would be if the user is looking only at the 300 Area and does some contouring. The contour lines may be skewed according to the boundary. Both of these problems are difficult to deal with in a GIS. A new release of ARC/INFO (Version 6.0) is supposed to allow the assignment of a constant value to dead areas. This approach may not satisfy the needs of some users. The HEISGIS development team has taken an iterative approach to find the best solution to these problems. The user's needs, implementability, time and cost, and project scope will be considered before making final decisions on how to handle complex spatial representation problems.

\subsubsection{Data Security}

Data security is a critical issue in many software packages. More security implies more access restrictions and more training requirements. Increased security may satisfy the users with high security needs, but may displease the users that value access convenience more than security. Therefore, the design decisions on the level of security and how it is applied among the various users is of critical importance. The data security strategy will be to ensure the integrity of the base maps through system-level security and requiring that user data be protected by each user.

\subsubsection{System Response}

The system response depends on the hardware used, the number of simultaneous users, and the data volume processed by the requested GIS operations. Some GIS operations take more than a few minutes to be completed, 
making them unsuitable for interactive use. Therefore, some batch processing will be a design requirement for HEISGIS.

\subsubsection{Contours}

Elevation contours will be stored as part of the base maps because they are verified as such. An alternative approach would be to store only the elevation points and then generate the contours. Although this latter alternative reduces disk storage requirements, it will not be used because it may decrease the verifled contour accuracy. Users need to be aware that storing the contours explicitly means that their large data size may create disk storage space problems and cause time delays in screen updates. Some users may choose not to store contours on their systen.

\subsubsection{Data}

The quality of the HEISGIS and its acceptance by the user community is directly dependent on the quality of the data it contains. As stated in Section 3.0, the data must be in Washington State Coordinates (NAD 83 meters with contours in meters). Any data that is not in this coordinate system will have to be translated into it.

The spatial attribute data contained in the HEIS database, in particular most of the well locations, are not all in WSC. Those well locations not in WSC must be translated into WSC. It is noted that the location accuracy of the wells in the non-WSC systems is highly questionable. Therefore, even if the translation process introduces no error, the resultant well location accuracy will be questionable. Limited re-surveying procedures may be required in order to increase the well location accuracy, but it is outside the scope of the HEISGIS development. 


\subsection{REFERENCES}

1. Westinghouse Hanford Company. 1990. "Hanford Environmental Information System (HEIS) User's Manual," October 1990, WHC-EP-0372, Rich1 and, Washington.

2. American Congress on Surveying \& Mapping and the American Society of Civil Engineering. 1978. Definitions of Surveying and Associated Terms, Appendix B. 
APPENDIX A

USER/ANALYSIS TEAM IDENTIFICATION 


\section{APPENDIX A \\ USER/ANALYSIS TEAM IDENTIFICATION}

The user or user group name, organizational affiliation, and expected interaction with the HEISGIS is provided below.

Systems Analysis Team:

Robert Burnett, PNL, Developer, (509) 375-2313

Paula Cowley, PNL, Project Manager, (509) 375-2282

Betty Evans, PNL, Developer, (509) 375-2394

Heidi Harty, PNL, Developer, (509) 375-2137

Elena Overton, PNL, Systems Analyst, (509) 375-2112

Spyros Tzemos, PNL, HEISGIS Task Leader, (509) 375-3683

Susan White, PNL, Developer, (509) 375-2171

Users:

HEIS Technical Advisory Committee -- GIS subconimittee:

Rick Bates, PNL, Data Accuracy

George Evans, WHC, Buffering

Jack Fassett, WHC, Display 3D models, Contouring

Byron Gesse1, KEH, Editing, Dimensional Calculations

Bob Hencke1, WHC, Display, Contouring

Tim Haggett, WHC, Base Map Data

A1 Lewis, KEH, Data Accuracy

Bob Raidl, WHC, Networking

Mike Schwab, WHC, Project Manager, (509) 376-4836

John Serkowski, WHC, Comparing/Combining Data, Cross

Sectioning

Randy Sma11, DOE, Base Map Data

Jim States, PNL, Comparing/Combining Data, Display 3D

Models, Contouring

Jim Young, PNL, Editing Data

\section{Other Agencies}

The HEIS HEISGIS will be used by a variety of people from the Department of Energy (DOE), the Environmental Protection Agency (EPA), and the Washington Department of Ecology (WDOE). 
APPENDIX B

ACRONYMS 
APPENDIX B

ACRONYMS

Term

Abbrev.

Acronym

ARC/INFO

Description

The GIS platform purchased from ESRI to develop and deliver the HEISGIS

ASCII

American Standard Code for Information Interchange (text files)

DBMS

Database Management System

DOE

Department of Energy

DXF

EPA

Data Exchange Format (used by Autocad to convert to ASCII)

ESRI

Environmental Protection Agency

GIS

Environmental Sciences Research Institute

HEIS

Geographic Information System

HTAC

KEH

Hanford Environmental Information System

HEIS Technical Advisory Committee

PNL

Kaiser Engineers Hanford

RDBIO

Pacific Northwest Laboratory

SIMS

ARC/INFO's Relational Database Interface

TPA

USGS

Spatial Information Management System

The Hanford Federal Facility Agreement and Consent Order, also known as the Tri-Party Agreenent

WDOE

United States Geological Survey

Washington Department of Ecology

WHC

Westinghouse Hanford Company 


\section{APPENDIX C}

FUTURE CONSIDERATIONS 


\section{APPENDIX C}

\section{FUTURE CONSIDERATIONS}

Functionalities listed here have been identified as desirable but, because these applications are likely to be too time consuming and costly, they are currently considered to be out of the scope of HEISGIS.

1. Modeling. The application of network flow theory to underground water flow will facilitate ground-water modeling. Interfaces between the existing ground-water models and HEISGIS will also enhance the modeling capabilities.

2. Animation. Time series data may be expressed in a series of screen displays using a compressed or expanded time scale in an animation mode. Real time computer animation is a very effective communication technique, useful in the understanding of physical phenomena, and its incorporation in HEISGIS could be investigated.

It is expected that additional improvements will be identified during the user testing period. A GIS enhancement software program is planned for FY92 to accommodate these user-derived optimizations. 
No. of

Copies

OFFSITE

12 DOE/Office of Scientific and Technical Information

ONSITE

3 DOE Richland Field Office

R. W. Small

N. A. Werdel

R. D. Wojtasek

12 Westinghouse Hanf ard Company

L. A. Dietz

G. C. Evans

J. W. Fassett

R. P. Henckel

T. 0. Haggett

R. F. Raidl

M. R. Schwab (5)

J. A. Serkowski

2 Kaiser Engineers Hanford

B. M. Gesse1

A. K. Lewis

21 Pacific Northwest Laboratory

D. J. Bates

R. A. Burnett

P. J. Cowley

B. J. Evans

H. H. Kemp

E. S. Overton

S. Tzemos (7)

S. G. White

J. S. Young

Publishing Coordination

Technical Report Files (5) 

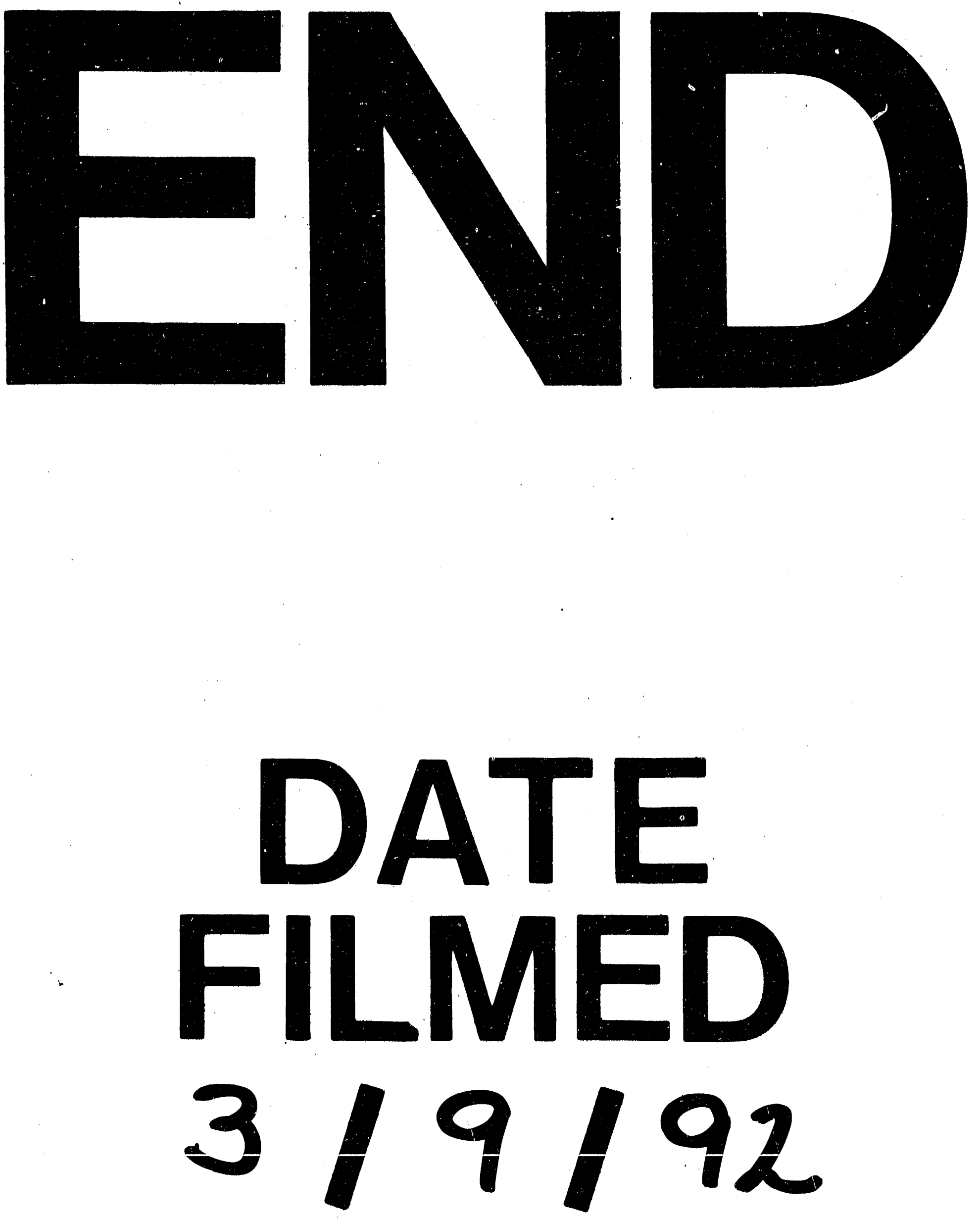
